\title{
ANÁLISE DOS CUSTOS E DA PRODUTIVIDADE DA SOJA CONVENCIONAL E TRANSGÊNICA NO BRASIL NOS ANOS DE 2017 E 2018
}

\author{
JULIANE ANDRESSA PAVÃO, \\ SIMONE BERNARDES VOESE.
}

\begin{abstract}
RESUMO - A pesquisa tem como objetivo analisar os custos e a produtividade da soja convencional e transgênica no Brasil no período de 2017 e 2018. Esse estudo se caracteriza como quantitativo e descritivo. Utilizou-se de dados secundários de custos da produção da soja, safras de 2017 e 2018, no Brasil, obtidos no site da Companhia Nacional de Abastecimento [4]. Os dados foram organizados numa planilha do Excel e posteriormente submetidos a testes estatísticos, como correlação de Spearman, teste T de Mann-Whitney e regressão linear múltipla, por meio do software Statistical Package for the Social Sciences (SPSS) versão 24. Os achados evidenciam que existem distinções entre os custos e produtividade entre a soja convencional e transgênica. Uma vez que os custos com agrotóxicos explicam $49 \%$ da produtividade da soja transgênica, e ainda, os custos com agrotóxicos possui diferença estatisticamente significativa em comparação com a soja convencional. Além disso, os custos com agrotóxicos apresentaram alta correlação com a produtividade e os custos de fertilizantes, resultado esse não encontrado para a soja convencional.
\end{abstract}

PALAVRAS-CHAVE - Custos; Produtividade; Soja.

\section{INTRODUÇÃO}

A soja é um dos principais produtos vinculados à cadeia produtiva da agropecuária brasileira, sendo ofertado no formato de grãos, farelos e óleos para o abastecimento do mercado interno e externo [5]. Segundo a CONAB [4], o Brasil caracteriza-se como o segundo maior produtor mundial, sendo que em 2017, apresentou área superior a 33 milhões de hectares [18]. Srivastava et al. [17] investigaram a produção da soja e identificaram que o adubo químico, os fertilizantes químicos e as máquinas influenciam significativamente na produção de soja. Já Salam e Kamruzzaman [10] verificaram que escassez de fertilizantes químicos devido a preço alto, falta de disponibilidade de sementes de qualidade, falta de conhecimento técnico e calamidades naturais são barreiras da expansão das lavouras de soja em Bangladesh.

Com a adoção de tecnologia de alimentos, houve uma segmentação da produção de soja em convencional (soja NGM) e o da soja transgênica (soja OGM), conforme destacam Leitão et al. [9]. Os organismos geneticamente modificados (OGMs) ou também conhecidos como transgênicos são obtidos por meio da alteração da estrutura biológica no qual é "compostas por ácidos desoxirribonucleicos ou ácidos ribonucleicos, que sofrem alterações de origem genética a partir de técnicas que resultem no acréscimo ou na remoção de uma nova característica fenotípica e/ou genotípica" (MINISTÉRIO DA AGRICULTURA, 2015 apud TABOSA et al., 2017, p. 45). Essa alteração tem como objetivo obter características diferentes das plantas naturais a fim de melhorar sua resistência a doenças, pragas e herbicidas, aumentando os compostos nutricionais, dando maior facilidade de processamento, melhor conservação, entre outras melhorias, porém vem sendo alvo de várias críticas [5].

Phélinas e Choumert [9] estudaram a sustentabilidade em longo prazo no cultivo de soja geneticamente modificada na Argentina. Os autores afirmam que as implicações ambientais da biotecnologia agrícola parecem alarmantes e a sustentabilidade em longo prazo das culturas OGM é altamente questionável [9]. Porém Silveira e Rezende [16] mencionam que existem afirmações em relação à redução de custos com os OGM em comparação a soja convencional, mas as evidências ainda não são sólidas. Dessa forma, a fim de auxiliar na elucidação desses argumentos contraditórios, esse estudo tem como problema a ser investigado: Qual a diferença entre os custos e a produtividade da soja convencional e transgênica no Brasil? A pesquisa tem como objetivo analisar os custos e a produtividade da soja convencional e transgênica no Brasil na produção de 2017 e 2018.

O estudo se justifica devido à necessidade de maiores informações a respeito dos custos e produtividade da soja convencional e transgênica. Bem como, pelo fato dos produtores enfrentarem problemas em relação à saúde financeira das propriedades, trazendo a análise de custos neste setor [2], sendo que o custo de produção agrícola é uma excepcional ferramenta de controle e gerenciamento das atividades produ- 
tivas e de geração de informações relevantes para as tomadas de decisões pelos produtores rurais [4].

\section{REFERENCIAL TEÓRICO}

Com o crescimento da população é necessário um número crescente de alimentos que são providos por meio da agricultura [16]. Dessa forma, a soja passou a ser um dos grãos mais produzidos e consumidos no mundo nas últimas três décadas [5].

O Brasil é o segundo maior produtor mundial de soja ficando atrás apenas dos Estados Unidos [4]. Porém, previsões indicam que o Brasil irá ultrapassar os Estados Unidos em 2018, assumindo a posição de maior produtor da soja pela primeira vez na história [11]. Os produtores de soja brasileiros vêm expandindo a área de plantio da soja pelos últimos 12 anos a fim de atender a demanda asiática [7]. A ultrapassagem do Brasil nos Estados Unidos como maior produtor do grão pode ocorrer devido melhorias logísticas, ganhos do plantio do milho como uma cultura de rotação, que aumentam o rendimento dos agricultores [11].

Segundo dados do CONAB [4], a soja é a cultura agrícola que apresenta maior volume de produção no Brasil, representando aproximadamente $48 \%$ do total de grãos produzidos. A produção da soja foi consolidada no Brasil a partir dos anos de 1980 e é uma das principais cadeias produtivas da agropecuária brasileira, ofertando grãos, farelos e óleos para o abastecimento do mercado interno e externo [5].

Desde 1940 a soja vem sendo cultivada no Estado do Rio Grande do Sul, avançando duas décadas depois para os Estados de Santa Catarina e Paraná e passando a ter grande importância econômica na região sul do país. Já em 1969, a região sul era responsável por $98 \%$ de toda a produção brasileira da soja [4]. Porém a soja ultrapassa esses limites territoriais e passa a se expandir nas demais regiões do país, mesmo naquelas onde o clima não seria tão propício [5].

De acordo com Silveira e Resende [16], a primeira soja transgênica comercializada surgiu da transformação genética de plantas por meio da engenharia genética e difere da soja convencional por possuir um gene que apresenta resistência ao herbicida de ação total denominado de glifosato, o que facilita o controle das ervas daninhas. A princípio o seu uso se generalizou em algumas regiões, porém, ao mesmo tempo, surgiram reações com críticas com relação à segurança dessa tecnologia.

O Estado brasileiro que passou primeiramente a adotar o plantio da soja transgênica em grande escala foi o Rio Grande do Sul, por meio do ingresso de variedades clandestinas da Argentina, onde o plantio da soja transgênica já era liberado há mais tempo. A principal justificativa para o uso da soja transgênica seria diminuição de custo pelo menor número de pulverizações e produtos para combater ervas daninhas [16].

Segundo Espíndola e Cunha [5], a soja transgênica predomina na plantação brasileira no cenário atual, e ainda, deverá cobrir $93 \%$ da área total de plantação. A soja convencional produzida é apenas para atender ao nicho de mercado, prin- cipalmente europeu, uma vez que esse mercado prefere pagar valores maiores para ter soja convencional.

Algumas cooperativas do Estado do Paraná, a fim de evitar possíveis barreiras às exportações, certificam que a sua produção seja de soja convencional. Ao mesmo tempo, por outro lado, a empresa multinacional detentora da patente do gene da soja modificada promulga uma inovação revolucionária tentando disseminá-la de forma generalizada, assegurando que essa tecnologia fornecerá comodidade e ganhos econômicos para os produtores [16].

A CONAB [4], a respeito da produtividade nas lavouras de soja convencional e transgênica, afirma que a evolução da produtividade nas lavouras de soja convencional tem crescimento semelhante ou até em casos superiores as lavouras de soja transgênica. Evidenciando que a opção por lavouras de soja convencionais ou transgênicas não é mais uma decisão embasada somente na obtenção de custos de produção mais eficientes. Ou seja, a opção pelo tipo de lavoura adotar deve buscar, não apenas a redução em seus gastos, mas também o mercado que se aspira atingir na comercialização do grão. Porém, o presente estudo se limita a investigar apenas as relações entre custos e a produtividade da soja convencional e transgênica, não adentrando em temas como o nicho de mercado. Dessa forma, com relação aos custos de produção da soja, estudos da CONAB [4], apontam que os custos mais representativos são os fertilizantes, os agrotóxicos, as operações com máquinas, as sementes e a depreciação de máquinas e implementos. Esses custos juntos representam quase $70 \%$ do custo total operacional.

Silveira [12] realizou entrevistas com sete atores do agronegócio para identificar argumentações sobre a soja transgênica. $\mathrm{O}$ autor verificou que argumentos positivos da soja transgênica foram: a praticidade de uso e o custo de produção mais baixo. Quanto aos argumentos negativos em relação à soja transgênica, verificou-se o maior custo das sementes transgênicas e dúvidas sobre sua produtividade.

Menegatti e Barros [8] realizaram um estudo comparativo de custos de produção de soja convencional e transgênica do Estado do Mato Grosso do Sul. Os autores identificaram um comportamento inferior dos gastos com herbicidas da soja transgênica em relação à soja convencional, além de apresentar menor custo por hectare de mão de obra. Já Bragagnolo et al. [1] analisaram os custos de produção da soja convencional e transgênica no Estado do Paraná e identificaram um menor custo para a produção da soja transgênica.

Silveira e Resende [16] buscaram determinar os fatores comparativos de custos de produção entre a soja convencional e a transgênica para subsidiar estratégias de decisão de atores do agronegócio. E verificaram que mesmo com a redução de custo pelo menor uso de herbicidas na soja transgênica, esse fato se minimiza diante o maior preço cobrado pela semente da soja transgênica, pela taxa tecnológica cobrada pelo uso do gene e pela menor produtividade.

Guzatti e Franco [7] estudaram os custos de produção e rentabilidade nas lavouras de soja convencional e transgênica no Estado do Mato Grosso nas safras de 2008 a 2014. Os 
autores descobriram que a soja transgênica apresentou custos superiores com químicos e sementes quando comparado aos custos da soja convencional. Com relação à rentabilidade, verificou-se ser superior para a soja convencional, devido aos menores custos de produção.

Silveira e Rezende [16] mencionam que dentre os argumentos favoráveis à introdução da soja transgênica no Brasil, o fator custo é o mais enfatizado, porém, entre os argumentos negativos, é mencionada a sua baixa produtividade. Dessa forma, são necessários maiores esclarecimentos sobre esses argumentos, bem como, estudos mais aprofundados sobre a redução de custo com o uso da soja transgênica, pois ainda são escassos no Brasil e muitas vezes o contexto relacionado a soja transgênica é constituída por um desequilíbrio de argumentos.

\section{PROCEDIMENTOS METODOLÓGICOS}

Esse estudo se caracteriza como quantitativo e descritivo. Utilizou-se de dados secundários de custos da produção da soja, safras de 2017 e 2018, no Brasil, obtidos no site da Companhia Nacional de Abastecimento [4]. Os dados foram organizados numa planilha do Excel e posteriormente submetidos a testes estatísticos, como correlação de Spearman, teste T de Mann-Whitney e regressão linear múltipla, por meio do software Statistical Package for the Social Sciences (SPSS) versão 24. As variáveis investigadas foram custos de operações com máquinas, mão-de-obra, sementes, fertilizantes, agrotóxicos, depreciação, total de custos variáveis, total de custos fixos e produtividade por hectare ( $\mathrm{kg} / \mathrm{ha})$. Obtevese um total de 40 observações para o ano de 2017 e 2018, sendo 30 observações para a soja transgênica e 10 para a soja convencional. Essas observações foram submetidas ao seguinte protocolo de análise:

Na próxima seção os dados da soja convencional e transgênica serão analisados conforme o evidenciado na Tabela 1.

\section{ANÁLISE DOS RESULTADOS}

A Tabela 2 mostra as estatísticas descritivas para a soja convencional. Verifica-se que a produtividade média da soja convencional para os anos de 2017 e 2018 foi de 3.208 quilos por hectare. O custo mais representativo foi o custo com agrotóxicos com média de $\mathrm{R} \$ 701,86$ por hectare.

Já a Tabela 3 apresenta as estatísticas descritivas para a soja transgênica. A produtividade média é de 3.093 quilos por hectare, valor esse inferior em comparação com a soja convencional (vide Tabela 2). Interessante observar também que o desvio padrão da soja transgênica $(327,66)$ é superior ao da soja convencional $(175,17)$, ou seja, a produtividade da soja transgênica está suscetível a uma maior variação em torno do valor de produtividade média.

O custo médio com maior representatividade na soja transgênica foi os fertilizantes, sendo gasto em média, R \$570,42 por hectare. Com relação ao custo total médio, percebese um custo inferior para a soja transgênica, no valor de $\mathrm{R} \$ 2.859,05$, já a soja convencional apresentou um custo total médio de $\mathrm{R} \$ 3.229,98$.
Verifica-se nas Tabelas 2 e 3 a normalidade dos dados para a soja convencional e transgênica, pois de acordo com Marôco [10] os dados normais devem apresentar assimetria inferior a 3 e a curtose inferior a 10 .

Apesar de ser verificadas por meio de estatísticas descritivas diferenças nos valores médios dos custos de produção da soja convencional e transgênica, é importante verificar se estas diferenças possuem validade estatística. Para tanto, foi realizado o teste de Mann-Whitney apresentado na Tabela 4.

Verificou-se por meio do teste $\mathrm{T}$ de Mann-Whitney a existência de diferenças significativas para os custos com fertilizantes, custos com agrotóxicos e o total de custos variáveis da produção da soja convencional e transgênica. As estatísticas descritivas apresentadas na Tabela 5 mostram que a média dos custos com fertilizantes, custos com agrotóxicos e o total de custos variáveis da produção da soja convencional são superiores aos custos da soja transgênica.

Tabela 5. Valores médios em reais para os custos que apresentaram diferença significante

\begin{tabular}{|l|l|l|}
\hline & Soja convencional & Soja transgênica \\
\hline Fertilizantes/ha & 680,68 & 570,42 \\
\hline Agrotóxicos/ha & 701,86 & 546,47 \\
\hline Custos variáveis/ha & 2277,42 & 1993,64 \\
\hline
\end{tabular}

Importante ressaltar que, com relação a sementes, não foi verificado diferenças descritivas nem estatisticamente significantes, contrapondo o mencionado pela literatura em que a semente da soja transgênica possui maior valor [12]. Segundo os dados analisados, a soja convencional apresentou gasto médio com sementes no valor de $\mathrm{R} \$ 233,64$ e a soja transgênica de $\mathrm{R} \$ 264,44$. Porém o custo de sementes para a soja transgênica está sujeita a maior variação (desvio-padrão de $\mathrm{R} \$ 105,85$ contra $\mathrm{R} \$ 32,78$ da soja convencional).

Em busca de maior entendimento entre a produtividade e os custos de produção, realizou-se a correlação comparativa das variáveis entre soja convencional e transgênica.

Os resultados da correlação dos dados da soja convencional apontam que quanto maior o custo de sementes maior é a produtividade apresentando uma correlação positiva e significativa de 0,96. E ainda, verifica-se na Tabela 6, que os custos com fertilizante apresentou correlação negativa e significante com a produtividade $(-0,64)$ e os custos com sementes $(-0,63)$. A Tabela 7 apresenta a correlação entre custos e produtividade da soja transgênica.

Já a soja transgênica mostrou forte correlação positiva entre os custos com fertilizantes e agrotóxicos $(0,68)$ e os custos de agrotóxico com a produtividade $(0,69)$, ou seja, quanto maior os custos de agrotóxicos utilizados maior será o custo de fertilizante e maior a produtividade.

Realizou-se também uma regressão linear múltipla tendo como variáveis independentes os custos de operações com máquinas, mão-de-obra, sementes, fertilizantes, agrotóxicos e depreciação, e como variável dependente a produtividade. Apenas os dados da soja transgênica atenderam os pressupos- 
Tabela 1. Procedimentos de análise estatística

\begin{tabular}{|l|l|l|l|}
\hline Etapa & Procedimentos & Objetivo & Suporte Teórico \\
\hline 1 & Estatística descritiva & Descrever o conjunto de dados & Field (2009) \\
\hline 2 & Assimetria e curtose & Verificar a normalidade dos dados & Marôco (2010) \\
\hline 3 & Teste T de Mann-Whitney & $\begin{array}{l}\text { Avaliar a diferença significativa entre os } \\
\text { grupos da soja convencional e OGM }\end{array}$ & Field (2009) \\
\hline 4 & Correlação de Spearman & $\begin{array}{l}\text { Avaliar a correlação das variáveis para } \\
\text { soja convencional e OGM }\end{array}$ & Marôco (2010) \\
\hline 5 & $\begin{array}{l}\text { Fator de inflação da Vari- } \\
\text { ância }\end{array}$ & $\begin{array}{l}\text { Detectar a presença de multicolineari- } \\
\text { dade }\end{array}$ & Field (2009) \\
\hline 6 & Regressão linear múltipla & $\begin{array}{l}\text { Verificar o poder de explicação dos custos } \\
\text { na produtividade da soja OGM }\end{array}$ & Field (2009) \\
\hline
\end{tabular}

Tabela 2. Estatísticas descritivas Soja Convencional $(n=10)$

\begin{tabular}{|l|l|l|l|l|l|l|}
\hline & Média & Mínimo & Máximo & $\begin{array}{l}\text { Desvio Pa- } \\
\text { drão }\end{array}$ & Assimetria & Curtos \\
\hline $\begin{array}{l}\text { Produtividade } \\
\text { kg/ha) }\end{array}$ & 3208,00 & 3000,00 & 3500,00 & 175,17 & 0,79 & $-0,07$ \\
\hline $\begin{array}{l}\text { Operações com } \\
\text { máq/ha }\end{array}$ & 188,81 & 99,81 & 456,17 & 125,60 & 1,74 & 1,67 \\
\hline MOD/ha & 42,42 & 0,00 & 282,82 & 95,44 & 2,28 & 4,77 \\
\hline Sementes/ha & 233,64 & 200,00 & 300,00 & 32,78 & 1,19 & 0,64 \\
\hline Fertilizantes/ha & 680,68 & 334,00 & 886,00 & 196,92 & $-1,12$ & 0,34 \\
\hline Agrotóxicos/ha & 701,86 & 469,58 & 967,64 & 159,51 & 0,02 & $-0,22$ \\
\hline Depreciação/ha & 473,52 & 171,62 & 1434,34 & 506,34 & 1,70 & 1,23 \\
\hline Custo variável/ha & 2277,42 & 2056,62 & 2595,84 & 208,74 & 0,80 & $-1,25$ \\
\hline Custo fixo/ha & 502,01 & 184,20 & 1459,64 & 508,59 & 1,64 & 1,09 \\
\hline $\begin{array}{l}\text { Custos } \\
\text { operacionais/ha }\end{array}$ & 2779,43 & 2252,92 & 3597,04 & 498,24 & 0,77 & $-0,61$ \\
\hline Custo total/ha & 3229,98 & 2394,47 & 4340,62 & 652,16 & 0,28 & $-0,98$ \\
\hline
\end{tabular}

Tabela 3. Estatísticas descritivas Soja Transgênica $(n=30)$

\begin{tabular}{|l|l|l|l|l|l|l|}
\hline & Média & Mínimo & Máximo & $\begin{array}{l}\text { Desvio Pa- } \\
\text { drão }\end{array}$ & Assimetria & Curtose \\
\hline $\begin{array}{l}\text { Produtividade } \\
\text { kg/ha) }\end{array}$ & 3093,00 & 2200,00 & 3600,00 & 327,66 & $-1,05$ & 2,51 \\
\hline $\begin{array}{l}\text { Operações com } \\
\text { máq/ha }\end{array}$ & 187,99 & 92,16 & 374,31 & 69,43 & 0,95 & 0,60 \\
\hline MOD/ha & 37,52 & 0,00 & 279,09 & 75,37 & 2,35 & 5,04 \\
\hline Sementes/ha & 264,44 & 142,50 & 592,50 & 105,85 & 1,80 & 3,03 \\
\hline Fertilizantes/ha & 570,42 & 280,68 & 795,80 & 157,01 & $-0,75$ & $-0,70$ \\
\hline Agrotóxicos/ha & 546,47 & 244,32 & 872,49 & 157,03 & 0,10 & $-0,41$ \\
\hline Depreciação/ha & 266,21 & 108,45 & 585,53 & 128,28 & 1,21 & 0,97 \\
\hline Custo variável/ha & 1993,64 & 1367,62 & 2619,22 & 337,09 & $-0,38$ & $-0,36$ \\
\hline Custo fixo/ha & 316,30 & 148,38 & 612,78 & 123,99 & 0,93 & 0,32 \\
\hline $\begin{array}{l}\text { Custos } \\
\text { operacionais/ha }\end{array}$ & 2309,95 & 1691,82 & 3232,00 & 380,90 & 0,21 & $-0,04$ \\
\hline Custo total/ha & 2859,05 & 2074,01 & 4176,14 & 471,67 & 0,85 & 1,33 \\
\hline
\end{tabular}

tos da regressão, devido esse motivo não são apresentados os resultados para a soja convencional.
Uma vez já verificado a normalidade dos dados, devese analisar o Fator de inflação da Variância (VIF) para dar 
Tabela 4. Teste de diferença de média para soja convencional e transgênica nos anos de 2017 e 2018

\begin{tabular}{|c|c|c|c|c|c|c|c|c|c|}
\hline & $\begin{array}{l}\text { Produti- } \\
\text { vidade }\end{array}$ & $\begin{array}{l}\text { Operaçõ } \\
\text { com } \\
\text { máq/ha }\end{array}$ & $\begin{array}{l}\text { SMOD } \\
\text { /ha }\end{array}$ & $\begin{array}{l}\text { Sementes } \\
\text { /ha }\end{array}$ & $\begin{array}{l}\text { Fertili- } \\
\text { zantes } \\
\text { /ha }\end{array}$ & $\begin{array}{l}\text { Agrotó- } \\
\text { xicos } \\
\text { /ha }\end{array}$ & $\begin{array}{l}\text { Deprecia- } \\
\text { ção/ha }\end{array}$ & $\begin{array}{l}\text { Custos } \\
\text { Variá- } \\
\text { veis/ha }\end{array}$ & $\begin{array}{l}\text { Custos } \\
\text { Fixos } \\
\text { /ha }\end{array}$ \\
\hline $\begin{array}{l}\text { U de Mann- } \\
\text { Whitney }\end{array}$ & 111,00 & 115,00 & 126,00 & 145,50 & 70,50 & 72,00 & 138,00 & 75,00 & 142,00 \\
\hline Wilcoxon W & 576,00 & 170,00 & 181,00 & 200,50 & 535,50 & 537,00 & 603,00 & 540,00 & 197,00 \\
\hline $\mathrm{Z}$ & $-1,23$ & $\begin{array}{l}-1,09 \\
\end{array}$ & $-0,86$ & $\begin{array}{l}-0,14 \\
\end{array}$ & $\begin{array}{l}-2,48 \\
\end{array}$ & $-2,44$ & $-0,37$ & $-2,34$ & $-0,25$ \\
\hline $\begin{array}{l}\text { Significância As- } \\
\text { sint. (Bilateral) }\end{array}$ & 0,22 & 0,27 & 0,39 & 0,89 & $0,01^{*}$ & $0,01^{*}$ & 0,71 & $0,02^{*}$ & 0,80 \\
\hline $\begin{array}{l}\text { Sig exata }[2 *(\text { Sig. } \\
\text { de unilateral)] }\end{array}$ & 0,23 & 0,29 & 0,47 & 0,89 & 0,01 & 0,01 & 0,72 & 0,02 & 0,82 \\
\hline
\end{tabular}

Tabela 6. Correlações entre custos e produtividade na safra da soja convencional em 2017 e 2018

\begin{tabular}{|l|l|l|l|l|l|l|}
\hline & $\begin{array}{l}\text { Produtivi- } \\
\text { dade }\end{array}$ & $\begin{array}{l}\text { Operações } \\
\text { com } \\
\text { máq/há }\end{array}$ & MOD/ha & $\begin{array}{l}\text { Sementes } \\
\text { /ha }\end{array}$ & $\begin{array}{l}\text { Fertilizantes } \\
\text { /ha }\end{array}$ & $\begin{array}{l}\text { Agrotóxicos } \\
\text { /ha }\end{array}$ \\
\hline Operações com máq/ha & 0,390 & - & - & - & - & - \\
\hline MOD/ha & $0,703^{*}$ & $0,701^{*}$ & - & - & - & - \\
\hline Sementes/ha & $0,963^{* *}$ & 0,380 & $0,703^{*}$ & - & - & - \\
\hline Fertilizantes/ha & $-0,642^{*}$ & $-0,050$ & $-0,703^{*}$ & $-0,634^{*}$ & - & - \\
\hline Agrotóxicos/ha & 0,520 & $-0,270$ & 0,030 & 0,410 & $-0,240$ & - \\
\hline Depreciação/ha & $-0,070$ & $0,830^{* *}$ & 0,350 & $-0,060$ & 0,360 & $-0,390$ \\
\hline *. A correlação é significativa no nível 0,05 \\
\hline **. A correlação é significativa no nível 0,01 \\
\hline
\end{tabular}

Tabela 7. Correlações entre custos e produtividade na safra da soja transgênica em 2017 e 2018

\begin{tabular}{|l|l|l|l|l|l|l|}
\hline & $\begin{array}{l}\text { Produtivi- } \\
\text { dade }\end{array}$ & $\begin{array}{l}\text { Operações } \\
\text { com } \\
\text { máq/há }\end{array}$ & MOD/ha & $\begin{array}{l}\text { Sementes } \\
\text { /ha }\end{array}$ & $\begin{array}{l}\text { Fertilizantes } \\
\text { /ha }\end{array}$ & $\begin{array}{l}\text { Agrotóxicos } \\
\text { /ha }\end{array}$ \\
\hline Operações com máq/ha & 0,190 & - & - & - & - & - \\
\hline MOD/ha & 0,050 & 0,240 & - & - & - & - \\
\hline Sementes/ha & 0,350 & $0,392^{*}$ & 0,000 & - & - & - \\
\hline Fertilizantes/ha & $0,412^{*}$ & $-0,378^{*}$ & $-0,492^{* *}$ & $-0,090$ & - & - \\
\hline Agrotóxicos/ha & $0,696^{* *}$ & $-0,090$ & $-0,300$ & 0,000 & $0,683^{* *}$ & - \\
\hline Depreciação/ha & $0,396^{*}$ & $0,680^{* *}$ & 0,130 & 0,230 & 0,080 & 0,270 \\
\hline *. A correlação é significativa no nível 0,05 \\
\hline **. A correlaçãó é significativa no nível 0,01 \\
\hline
\end{tabular}

continuidade na análise de regressão. A Tabela 8 mostra que o maior valor de VIF é de 3,634 para a variável Operações com máquinas, sendo assim, os dados não possuem multicolinearidade [6].

A regressão linear múltipla mostrou-se significativa com um $\mathrm{R}^{2}$ de $79 \%$. As variáveis que se mostraram significativas $(\mathrm{p}<0,05)$ e os respectivos coeficientes padronizados são: mão-de-obra (47\%), agrotóxicos (49\%) e depreciação (46\%). Ou seja, a mão-de-obra, os agrotóxicos e a depreciação dos equipamentos e máquinas estão associados positivamente com a produtividade da soja transgênica.

\section{CONSIDERAÇÕES FINAIS}

O estudo teve como objetivo analisar as diferenças entre os custos de produção e a produtividade da soja convencional e transgênica no Brasil nas lavouras de 2017 e 2018. Por meio de análises estatísticas, pode-se concluir que existem distinções entre os custos de produção e produtividade entre a soja convencional e transgênica.

Verificou-se que os custos com agrotóxicos explicam $49 \%$ da produtividade da soja transgênica, sendo que os custos com agrotóxicos possuem diferença estatisticamente significativa em comparação com a soja convencional. E ainda, 
Tabela 8. Coeficientes da regressão múltipla em soja transgênica para os anos de 2017 e 2018

\begin{tabular}{|c|c|c|c|c|c|c|}
\hline & \multicolumn{2}{|c|}{ Coeficientes não padronizados } & \multirow{2}{*}{$\begin{array}{l}\text { Coeficientes padronizados } \\
\text { Beta }\end{array}$} & \multirow{2}{*}{$\mathbf{t}$} & \multirow{2}{*}{ Sig. } & \multirow{2}{*}{ VIF } \\
\hline & $\mathbf{B}$ & Erro Padrão & & & & \\
\hline (Constante) & 1990,295 & 192,165 & & 10,357 & 0,000 & - \\
\hline Operações com máq/ha & $-0,467$ & 0,851 & $-0,099$ & $-0,549$ & 0,589 & 3,634 \\
\hline MOD/ha & 2,054 & 0,473 & 0,473 & 4,341 & $0,000^{*}$ & 1,322 \\
\hline Sementes/ha & 0,303 & 0,356 & 0,098 & 0,852 & 0,403 & 1,478 \\
\hline Fertilizantes/ha & 0,272 & 0,351 & 0,130 & 0,775 & 0,446 & 3,158 \\
\hline Agrotóxicos/ha & 1,031 & 0,282 & 0,494 & 3,661 & $0,001 *$ & 2,035 \\
\hline Depreciação/ha & 1,181 & 0,393 & 0,462 & 3,003 & $0,006^{*}$ & 2,647 \\
\hline
\end{tabular}

os custos com agrotóxicos apresentou alta correlação com a produtividade e os custos de fertilizantes, resultado esse não encontrado para a soja convencional.

Alguns achados estão de acordo com a literatura pesquisada, no qual se apresentaram maiores custos totais de produção para a soja convencional e menor produtividade na soja transgênica [16]. Porém, no que se refere ao valor gasto com sementes, não se verificou diferença estatística significante, sendo o valor da semente para a soja transgênica apresentouse pouco mais caro em comparação com a soja convencional. Ao contrário do que afirmam Silveira e Resende [16], os quais mencionam que a semente da soja transgênica teria um maior preço cobrado devido à taxa tecnológica cobrada pelo uso do gene.

Esse estudo buscou reduzir os argumentos contraditórios presentes na literatura a respeito da produtividade e dos custos de produção para a soja convencional e transgênica. Porém os resultados encontrados não podem ser generalizados e possui algumas limitações, como o fato de possuir observações de diferentes regiões do Brasil que possuem distintas características climáticas, sendo esse um fator que motivar a produtividade, bem como, os custos de produção. Assim, sugere-se para futuras pesquisas investigar os custos e produtividade da soja convencional e transgênica em regiões com condições climáticas semelhantes, e ainda, uma análise que compreenda um maior período de tempo.

\section{Referências}

[1] BRAGAGNOLO, C.; MAFIOLETTI, R. L.; SBISSIA, G. F.; TURRA, F. E. Análise dos custos de soja no Paraná: Convencional x Transgênica. Anais... XLIII Congresso Brasileiro de economia e Sociologia Rural. SOBER. Londrina-PR: 2007.

[2] CAllado, A. L. C.; ALMEIDA, M. A. Perfil dos artigos sobre custos no agronegócio publicados nos anais do Congresso Brasileiro de Custos. Custos e agronegócio online, v. 1, n. 1, p. 42-61, jan./jun. 2005.

[3] CONAB. Evolução dos custos de produção de soja no Brasil. Compêndio de estudos CONAB, v. 2, 2016. Brasília: CONAB, 2016. Disponível em: < https://www.conab.gov.br/institucional/publicacoes/compendio-deestudos-da-conab/item/download/2512_c2638f76696e3b926ab22e93f9549d21>. Acesso em: 10 set. 2018.

[4] CONAB. Companhia Nacional do Abastecimento. 2018. Disponível em: < https://www.conab.gov.br/ >. Acesso em: 10 set. 2018.

[5] CUNHA, R. C.; ESPÍNDOLA, C. J. A dinâmica geoeconômica recente da cadeia produtiva da soja no Brasil e no mundo. GeoTextos, v. 11, n. 1, 2015.
[6] FIELD, A. Descobrindo a estatística usando o SPSS. 2. ed. Porto Alegre: Artmed, 2009.

[7] GOMES, J. R. Agricultores brasileiros prontos para plantar uma área recorde de soja em 2018-19: pesquisa. Ago 2018. Disponível em: < https://www.reuters.com/article/us-brazil-grains-soybeans/brazil-farmerspoised-to-plant-record-soy-area-in-2018-19-poll-idUSKCN1L61X5> Acesso em: 18 out. 2018.

[8] GUZATTI, N. C.; FRANCO, C. Custo de produção e rentabilidade para a cultura da soja nas variedades convencional e transgênica em Mato Grosso. Revista UNEMAT de Contabilidade, v. 4, n. 8, Ago./Dez. 2015.

[9] LEITÃO, F. O.; SILVA, W. H.; GRANEMANN, S. R.; RIBEIRO, J. G. B. L. Mudanças organizacionais no sistema agroindustrial (sag) da soja pós inovação tecnológica dos transgênicos. Brazilian Journal of Management Innovation, v. 5, n. 3, p. 145-171, 2018.

[10] MARÔCO, J. Análise de equações estruturais: Fundamentos teóricos, software aplicações. Lisboa: ReportNumber, 2010.

[11] MENEGATTI, A. L.; BARROS, A. L. M. Análise comparativa dos custos de produção entre soja transgênico e convencional: um estudo de caso para o estado do Mato Grosso do Sul. Revista de Economia Rural, Rio de Janeiro, v. 45, p. 163-183, 2007.

[12] PHÉLINAS, P.; CHOUMERT, J. Is GM soybean cultivation in Argentina sustainable?. World Development, v. 99, p. 452-462, 2017.

[13] SALAM, M. A.; KAMRUZZAMAN, M. Comparative and competitive advantage of soybean cultivation in Noakhali and Laxmipur District of Bangladesh. Journal of the Bangladesh Agricultural University, v. 13, n. 2, p. 265-272, 2016.

[14] SAMORA, R. Brasil vai passar nos EUA como maior produtor de soja do mundo em 2018. maio 2018. Disponível em: $<$ https://www.reuters.com/article/us-brazil-soy-usa/brazil-to-pass-u-s-asworlds-largest-soy-producer-in-2018-idUSKBN1IC2IW>. Acesso em: 18 out. 2018.

[15] SILVEIRA, J. V. F. Estratégia de segmentação de mercado no agronegócio: o caso da inserção da soja transgênica no estado do Paraná. 2005. 141 p. Dissertação (Mestrado em Engenharia de Produção) - Universidade Tecnológica Federal do Paraná, 2005.

[16] SILVEIRA, J. V. F.; RESENDE, L. M. Estratégias de mercado no agronegócio paranaense: soja convencional vs. transgênica. Produção [online], São Paulo, v. 20, n. 1, 2010.

[17] SRIVASTAVA, S. C.; GUPTA, B. S.; TOMAR, S. S.; SINGH, H. P. Economics of production and Resource use efficiency of soybean production in India. Economic Affairs, v. 60, n. 2, p. 347, 2015.

[18] USDA. World Agricultural Supply and Demand Estimates. September 12 2018. Disponível em: < https://www.usda.gov/oce/commodity/wasde/>. Acesso em: 20 out. 2018. 


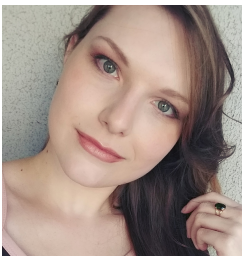

JULIANE ANDRESSA PAVÃO

Professora do Departamento de Ciências Contábeis da Universidade Estadual de Maringá e doutoranda no Programa de Pós-Graduação em Contabilidade da Universidade Federal do Paraná (PPGCONT UFPR).

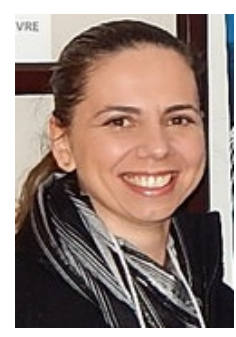

SIMONE BERNARDES VOESE

Possui graduação em Ciencias Contabeis pela Universidade do Vale do Itajaí (1996), mestrado em Engenharia de Produção pela Universidade Federal de Santa Catarina (1999) e doutorado em Engenharia de Produção pela Universidade Federal de Santa Catarina (2006) e pós-doutorado em Administração pela Universidade Federal do Mato Grosso do Sul (2017). Atualmente é professora associada da Universidade Federal do Paraná. 